
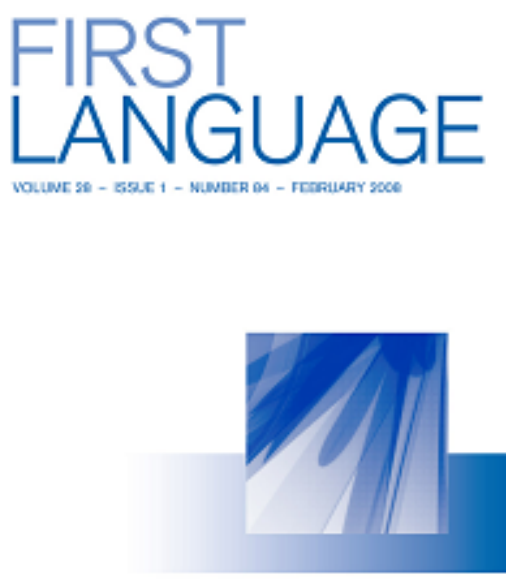

\title{
Reference maintenance in the narratives of Albanian-Greek and Russian-Greek children with Developmental Language Disorder: a study on crosslinguistic effects
}

\begin{tabular}{|c|l|}
\hline Journal: & First Language \\
\hline Manuscript ID & FLA-19-0043.R4 \\
\hline Keywords: & $\begin{array}{l}\text { Developmental Language Disorder, bilingualism, D elements, } \\
\text { crosslinguistic variation, Greek, Russian, Albanian, oral narratives }\end{array}$ \\
\hline & $\begin{array}{l}\text { Although a considerable number of studies have shown D (eterminer) } \\
\text { elements, i.e. determiners and pronominal clitics, to be particularly } \\
\text { vulnerable to impairment in monolingual children with Developmental } \\
\text { Language Disorder (DLD), little is known about the use of appropriate } \\
\text { or/and grammatically correct referring expressions in the children's } \\
\text { narrative production. Grammars of languages that differ in the way they } \\
\text { encode and realize their D system may be viewed as the ideal context to } \\
\text { disentangle the contribution of language (L1) transfer and morpho- } \\
\text { syntactic impairment to reference use in the L2. The aim of the current } \\
\text { study is to examine L1 effects in the use of referring expressions of 5- to } \\
\text { 11-year-old Albanian-Greek and Russian-Greek children with DLD, along } \\
\text { with TD bilingual groups speaking the same language pairs when } \\
\text { maintaining reference to characters in their narratives. The three } \\
\text { languages differ in their D elements, since Albanian and Greek have } \\
\text { morphologically rich D systems in contrast to Russian which lacks a } \\
\text { definiteness distinction. Children produced oral narratives in Greek by } \\
\text { using the Greek versions of two stories (Cat and Dog) which have been } \\
\text { designed within the Multilingual Assessment Instrument for Narratives } \\
\text { (MAIN) tool (Gagarina, Klop, Kunnari, Tantele, Välimaa, Balčiuniene, } \\
\text { Bohnacker, \& Walters, 2012) of the CoST Action IS0804. Results show } \\
\text { that the groups did not differ in referential appropriateness. Regarding } \\
\text { grammatical correctness, both groups with DLD produced more }\end{array}$ \\
\hline
\end{tabular}


ungrammatical forms than TD children, while Russian-Greek children with DLD produced more ungrammatical article-less NPs than the other groups. The overall results reflect the joint contribution of language impairment and L1-specific typological properties indefinite forms used for character maintenance by bilingual children with DLD.

\section{SCHOLARONE Manuscripts}




\begin{abstract}
Although a considerable number of studies have shown D (eterminer) elements, i.e. determiners and pronominal clitics, to be particularly vulnerable to impairment in monolingual children with Developmental Language Disorder (DLD), little is known about the use of appropriate or/and grammatically correct referring expressions in the children's narrative production. Grammars of languages that differ in the way they encode and realize their D system may be viewed as the ideal context to disentangle the contribution of language (L1) transfer and morpho-syntactic impairment to reference use in the L2. The aim of the current study is to examine L1 effects in the use of referring expressions of 5- to 11-year-old Albanian-Greek and Russian-Greek children with DLD, along with TD bilingual groups speaking the same language pairs when maintaining reference to characters in their narratives. The three languages differ in their D elements, since Albanian and Greek have morphologically rich D systems in contrast to Russian which lacks a definiteness distinction. Children produced oral narratives in Greek by using the Greek versions of two stories (Cat and Dog) which have been designed within the Multilingual Assessment Instrument for Narratives (MAIN) tool (Gagarina, Klop, Kunnari, Tantele, Välimaa, Balčiūnienè, Bohnacker, \& Walters, 2012) of the COST Action IS0804. Results show that the groups did not differ in referential appropriateness. Regarding grammatical correctness, both groups with DLD produced more ungrammatical forms than TD children, while Russian-Greek children with DLD produced more ungrammatical article-less NPs than the other groups. The overall results reflect the joint contribution of language impairment and L1-specific typological properties indefinite forms used for character maintenance by bilingual children with DLD.
\end{abstract}

Key words: Developmental Language Disorder, bilingualism, D elements, crosslinguistic variation, Russian, Greek, Albanian, oral narratives 


\section{Introduction}

Bilingual children with Developmental Language Disorder (DLD) have been shown to exhibit greater sensitivity to the givenness (given vs. new information) of referential descriptions in narrative production tasks relative to their monolingual peers with DLD (Tsimpli, Peristeri \& Andreou, 2016a). This sensitivity allows them to produce more appropriate referring expressions than their monolingual DLD peers depending on the discourse status that the expressions signal in the narratives. However, the use of referring expressions in bilingual children with DLD has only been tested in languages with similar referential systems (e.g. Greek and Albanian). Of special interest in this context is whether bilingual children with DLD can appropriately produce pronouns and other referring expressions in their narrative production in the second language (L2), when D elements, i.e. determiners and pronominal clitics, are not available in their first language (L1). The aim of the present study is to investigate whether the typological distance between bilingual DLD children's languages influences the choice and the morpho-syntactic realization of referential forms when the referents are maintained in narrative production. To this end, we investigated the oral narratives of two groups of bilingual children with DLD (Albanian-Greek, Russian-Greek), along with two groups of typically-developing (TD) Albanian-Greek and Russian-Greek children. Crucially, the language pairs of the bilingual groups of the current study display asymmetric typological properties in expressing definiteness; Albanian, like Greek, has formal marking of definiteness, while Russian lacks a definiteness distinction. Children's reference use was assessed in their L2/Greek with the Multilingual Assessment Instrument for Narratives (MAIN) tool (Gagarina, Klop, Kunnari, Tantele, Välimaa, Balčiūnienè, Bohnacker, \& Walters, 2012), which was developed within the COST Action IS0804 "Language Impairment in a Multilingual Society: Linguistic Patterns and the Road to Assessment".

The present study looks at the effects of L1 transfer and language impairment on maintaining character reference in narratives. Specifically, the aim is to examine children's referential adequacy and grammatical skills after the characters in the narrative have been introduced. The reasons for focusing on reference maintenance rather than the functions of introducing referents or reintroducing them after reference has shifted to a different character in the narrative are twofold. First, maintenance offers greater flexibility in terms of referential form choices than introduction or reintroduction, since introducing characters is accomplished through indefinite NPs (if the language has such a form), while switching reference to a reintroduced character is mainly accomplished through the use of explicit referential forms (i.e. definite NPs). On the other hand, maintaining reference can be accomplished through the use of pronominal clitics, null subject pronouns (in pro-drop languages), as well as definite NPs, depending on the degree of ambiguity created for the listener in the unfolding discourse. Greater variety of referential forms in the children's narratives would allow us to decouple effects of 
L1 transfer and language impairment in reference use more efficiently than in introduction or reintroduction. Second, reintroduction has been claimed to tap into more domain-general cognitive resources in TD children, such as working memory and executive attention, than maintenance (Colozzo \& Whitely, 2014; Peristeri \& Tsimpli, in press; Torregrossa, 2017). As such, reference use in reintroduction may be confounded by cognitive control deficits that have been frequently reported for both monolingual and bilingual children with DLD (Engel de Abreu, Cruz-Santos, \& Puglisi, 2014; Laloi, de Jong, \& Baker, 2017; Peristeri, Baldimtsi, Durrleman, \& Tsimpli, 2019). Since we were mainly interested in investigating possible L1 transfer and language deficit effects on children's use of referential forms, we assumed that the children's performance in maintaining reference would be less affected by non-linguistic factors, such as working memory or/and attention, that the present study did not control for.

$\mathrm{D}$ (eterminer) elements have been shown to be particularly vulnerable to impairment in monolingual children with DLD. Such weaknesses have been claimed to arise from difficulties with word retrieval and syntactic mastery of pronouns and articles (Miranda, McCabe, \& Bliss, 1998). Especially, clitic production has been found to be systematically deficient in DLD across a wide range of languages (e.g. Arosio et al., 2010 for Italian; Bedore \& Leonard, 2001; De La Mora, Paradis, Grinstead, Flores, \& Cantu, 2004 for Spanish; Chondrogianni \& Marinis, 2015 for English; Jakubowicz, Nash, Rigaut, \& Gerard,1998 for French; Tsimpli, Peristeri, \& Andreou, 2013 for Greek). Clitic omission and/or inappropriate morpho-phonological marking of clitics with wrong gender, person, case or/and number features (or else, clitic substitution errors) have been proposed to constitute a hallmark of the grammatical deficit in DLD in singlesentence, clitic elicitation tasks. Besides the grammatical deficit being widely observed in DLD, there is reason to suspect that levels of referential adequacy in children with DLD fluctuate depending on the lexical and syntactic complexity of the story, and, consequently, the load imposed by language demands on the children's narrative performance. Relevant research has proposed that encoding and recalling pictorial narratives in children with DLD critically relies on their expressive vocabulary and morpho-syntactic skills (Bishop \& Donlan, 2005; Miranda et al., 1998; Tsimpli, Peristeri, \& Andreou, 2016b). So far, none of these variables has been manipulated systematically in studies investigating reference use in bilingual children with DLD, so it remains unclear what specific factors might influence referential adequacy and grammatical skills in encoding reference in the specific population. The present study addresses this question by examining the role of children's language skills, more specifically, expressive vocabulary and sentence repetition, in their referential abilities.

A number of studies have investigated children's ability to facilitate a listener's identification of referents with their referential choices. The explicitness of expressions produced by children with DLD has been mainly examined in relation to the information status of referents in narrative tasks. These studies have shown that children with DLD are able to 
make use of discourse knowledge to both produce appropriate referring expressions and dynamically update the discourse model following a change of referent status in the unfolding story. For example, children with DLD have been shown to prefer NPs for (re)introducing referents just as chronological-age-matched TD children do (de Weck \& Jullien, 2013; Norbury \& Bishop, 2003; van der Lely, 1997), and to produce pronouns for maintaining reference to previously mentioned referents (Norbury \& Bishop, 2003; van der Lely, 1997). Children with DLD have also been found to show sensitivity to the grammatical role of the referent (Schelletter \& Leinonen, 2003); along with their TD peers, they tended to produce higher proportions of pronouns in subject position compared to object position, which was probably motivated by the fact that the syntactic subject position is by default associated with topics, i.e. entities whose propositional content has already been activated in discourse.

On the other hand, some studies report differences between children with DLD and TD children with respect to the informativeness of their referential choices in narratives. Recently, Peristeri and Tsimpli (in press) found that while monolingual children with DLD were efficient at producing morpho-phonologically correct referential forms, including clitics, overt pronouns, and (in)definite NPs, in an oral narrative task in which characters needed to be suitably introduced, maintained and reintroduced, they tended to produce more lexical NPs relative to pronouns for maintaining reference to an entity; the proportions of lexical NPs in children with DLD were also significantly higher than those of their TD peers. The observed over-specification in referential forms was found to correlate with DLD children's attention shifting performance, thus suggesting that their referential choices probably reflect non-verbal executive attention deficits that affected their ability to shift their focus of attention from one referent to another and update the status of the referents in unfolding discourse. Likewise, van der Lely (1997) found that even when controlling for differences in verbal age, children with DLD produced more lexical NPs than TD controls in contexts where at least two referents were present and which required a reintroduction of the referent. Norbury and Bishop's (2003) study, on the other hand, suggests an opposite pattern of referential performance than Peristeri and Tsimpli's (in press) and van der Lely's (1997) results. In their study, children with DLD produced more referentially ambiguous pronouns, meaning that they produced fewer NPs in discourse contexts where more than one referent was active and, hence, ambiguity could arise. Taken together, the findings so far indicate that children with DLD sometimes use higher numbers of overspecified or underspecified referential forms than age-matched TD children, pointing towards an inability to sufficiently take the addressee's perspective into consideration.

While the literature on L1 acquisition of D elements in monolingual children with DLD is vast, studies on the use of referential forms in bilingual children with DLD is scant. Tsimpli and colleagues' (2016a) narrative study with Albanian-Greek children with DLD and monolingual Greek-speaking children with DLD shows that monolingual children tended to 
produce more clitic omissions and clitic substitution errors than their bilingual peers with DLD in narrative production, as compared to a clitic elicitation task that was administered to the same group of children. The reported decline in errors in the oral narrative task raises the possibility that clitic misuse decreased when bilingual children with DLD were required to integrate referents in coherent discourse, to pre-plan their utterances and monitor the syntactic dependencies between referents and referential forms. However, the typological proximity between Greek and Albanian in terms of their D systems cannot provide evidence for languagespecific biases that may have affected bilingual DLD children's computation of referring expressions in narrative production. Interestingly, Gagarina's (2012) narrative study also revealed higher rates of referential cohesive devices by 4- and 5-year-old early Russian-German sequential TD bilingual children, which expands evidence on the benefits that bilingualism may provide in children's narrative production.

In a subsequent study, Tsimpli, Peristeri, and Andreou (2017) examined reference use in the narrative performance of 7- to 9-year-old, Russian-Greek children with and without DLD. Bilingual children with DLD exhibited higher proportions of determiner and clitic omissions, as well as more clitic substitution errors than their age-matched TD Russian-Greek peers, thus suggesting a grammatical deficit in functional categories related to the D system in Greek for the bilingual group with DLD. Though Tsimpli et al.'s (2017) findings could potentially be attributed to a negative morpho-syntactic L1 transfer effect from the Russian article-less system to the children's L2/Greek rather than to a grammatical deficit, the lack of comparable data from a group of children speaking languages with similar D systems did not allow us to contrast language impairment and L1 transfer effects in the bilingual children with DLD. To test this hypothesis, we have replicated Tsimpli and colleagues' (2017) study by comparing reference use in Russian-Greek and age-matched Albanian-Greek children with and without DLD in oral narratives elicited by the Greek versions of two stories (Cat and Dog).

\section{Determiner systems in Greek, Albanian and Russian}

The Greek and Albanian D systems pattern alike, at least with respect to the fact that both languages allow referential null and pronominal subjects. Null subject pronouns are reported to be used in topic-continuity contexts, in which one can draw an identity relation between the null pronoun and the context-induced topic (Andreou, Tsimpli, Kananaj \& Kapia, 2016; Papadopoulou, Peristeri, Plemenou, Marinis \& Tsimpli, 2015). Though definiteness is grammaticalized in both Greek and Albanian, the means of encoding it are different between the two languages, at least with respect to the definite article. In Greek, definite and indefinite articles are separate phonological entities and precede the noun stem (see underlined phrases in example 1). Bare nouns in object positions are licensed in certain contexts in Greek, despite the 
much more restrictive use of bare nouns in subject position (Dimitriadis, 1994; Sioupi, 2002). In Albanian, the definite article is suffixed to the noun stem and relies on case endings exclusively, while the indefinite article nje ' $\mathrm{a} / \mathrm{an}$ ' is a free element which always precedes the noun (see underlined phrases in example 2). Both Greek and Albanian have object pronominal clitics with distinct morphological inflections for accusative, dative (for Albanian) and genitive (for Greek) case (see underlined phrases in examples $3 \& 4$ for Greek and Albanian, respectively). Clitics in both languages precede verb forms (proclitics)) in matrix and embedded clauses, and show morphological agreement with the $p h i$-features (i.e. case, number, gender, and person) of the object of the verbs. Moreover, both Greek and Albanian have strong (or full) pronouns (aftos 'this/it' in Greek; kjo 'this/it' in Albanian), which are inflected for case, number, and gender, and are used both deictically and anaphorically in both subject and object position.

(1) $\underline{0}$ lavos

ke mia skilitsa the.SG.MASC.Nom rabbit.SG.MASC.NOM and a.SG.Fem.Nom dog. SG.FEM.NOM skeftikan na pane mia thought of.PAST.ACT.IND.3PL going. PAST.ACT.CONJ.3PL for a.SG.FEM.Acc volta walk.SG.FEM.Acc 'The rabbit and a dog-girl decided to go for a walk.' (GR)

(2) Shtepia eshte atje house.SG.MASC.NOM the.SG.MASC.NOM is.PRES.3 Sg there 'The house is there.' (AL)

(3) Pro tus ayorazi ¿jo balonia them.PL.MASC.ACC buys.PRES.Act.Conj.3PL two balloons. PL.NeUt.ACC 'She buys them two balloons.' (GR)

(4) $\underline{\text { Nje }}$ shtepi eshte atje. a.SG.FEM.Nom house.SG.MASC.NOM is.PRES.3 Sg there 'A house is there.' (AL)

Russian, on the other hand, is generally considered to be a partial pro-drop language. Different from consistent null subject languages (like Greek, Italian and Spanish), pro-drop in Russian is not licensed by verbal agreement or other morpho-syntactic factors but occurs in certain pragmatically motivated contexts that allow the listener to recover the referent of the null subject pronoun from the linguistic and sometimes the non-linguistic, situational context (Franks, 1995; Gordishevsky \& Avrutin, 2003). Within this frame, Russian normally licenses subject pronoun omission in specific discourse conditions that make pro-drop in Russian much less common than in other canonical null subject languages (Perlmutter \& Moore, 2002). Furthermore, and, in contrast to other languages in which the use of overt subject pronouns is consistently motivated by the need to signal a topic-shift function in discourse (Carminati, 
2002; Papadopoulou et al., 2015), overt subject pronouns in Russian can be unmarked, in the sense that they do not necessarily signal focus emphasis, stress or a shift of topic in discourse (Gordishevsky \& Avrutin, 2003). On the other hand, object omission is possible and preferred, provided certain subtle contextual requirements are satisfied, such as knowledge of old versus new information, or if the referent to be dropped lies in the center of discourse and the interlocutors' attention.

Finally, Russian is an article-less and non-clitic language. The eventual semantic interpretation of a NP, i.e. whether it is definite or indefinite, depends on the information structure and the word order of the sentences (see underlined phrases in examples $5 \& 6$ ). Though Russian does not mark specificity overtly, it has a range of indefinite pronouns (equivalent to some and any in English), which do mark different degrees of specificity for NPs (Dahl, 1970; Franks \& King, 2000; Gülzow \& Gagarina, 2007; Haspelmath, 1997; Ioup, 1977). To mark definiteness, Russian has demonstratives (e.g. etot 'this'; see underlined phrase in example 7), which are nevertheless mostly used to fulfil deictic functions in contrastive contexts rather than mark a NP as definite (Bailyn, 1995).
(5) Na stole lezhít karta
on table.SG.MASC. lies.PRES.Act.3SG map.SG.FEM
'There is a map lying on the table.' (RUS)
(6) Karta lezhít na stole
map.SG.FEM lies.PrES.Act.3SG on table.SG.MASC
'The map is lying on the table.' (RUS)
(7) eto mokroe
this. SG.NEUT wet. SG.NEUT
'This is wet.' (RUS)

\section{The current study}

The present study seeks to investigate the use of referring expressions in the narrative performance of twenty-five 5- to 11-year-old Albanian-Greek bilingual children with and without DLD, and two groups of age-matched Russian-Greek bilingual children with and without DLD. Crucially, we focused on the referential appropriateness and grammatical correctness of children's referring expressions. The specific set up allowed us to investigate whether differences in the use of referentially (in)appropriate and (un)grammatical expressions depended on the children's diagnosis (DLD, TD), their first language (Russian, Albanian), or both, thus, highlighting the role of cognitive and language-specific differences in reference use in narration. Furthermore, we were interested in investigating whether the two bilingual groups 
with DLD would differ from their TD peers in the types of the grammatical errors they would commit on their referring expressions. For example, Tsimpli et al. (2016a) found that bilingual Albanian-Greek children with DLD made fewer clitic substitution errors in oral narratives compared to a clitic elicitation task. We thus wanted to see whether the present study would replicate Tsimpli et al.'s (2016a) finding in the oral narrative task.

MAIN contains 4 picture-based stories, namely, Cat, Dog, Baby birds, and Baby goats, each illustrated with a six-picture sequence (Gagarina et al., 2012). The Cat/Dog and the Baby birds/Baby goats stories were originally designed for retelling and telling, respectively (Gagarina et al. 2012, 2015, p. 256). The use of referring expressions in the present study was assessed through the Greek versions of the Cat and Dog stories. Each story contains three main characters (i.e. the cat, the butterfly and the boy in the 'Cat' story; the dog, the mouse and the boy in the 'Dog' story). Oral narratives were elicited in the children's L2, i.e. Greek. We should note that, though the Cat/Dog stories were designed and aimed for retelling, the two stories were used for telling/story generation in the current study. The particular choice was driven by (a) the pictorial stimuli of the stories, and (b) the age range of our participants. More specifically, the pictures making up the Cat/Dog stories included characters/noun phrases that are marked with masculine and feminine grammatical gender in Greek (e.g. skilos 'dog.MASC', yata 'cat.FEM', petalu $\delta a$ 'butterfly.FEM'), while the main characters in the Baby goats/Baby birds stories correspond to neuter noun phrases in Greek (e.g. katsikaki 'baby goat.NEUT', pulaki 'baby bird.NEUT' puli 'mother-bird.NEUT'). Since all neuter nouns in Greek, and their corresponding strong overt pronouns and clitics, have identical morphophonological forms across the nominative and accusative case, when they appear in the syntactic subject and object position, respectively, we believed that using the Baby goats/Baby birds stories would potentially downplay the manifestation and variability of (especially, DLD) children's grammatical errors on (strong and clitic) pronouns, which constituted two of the current study's experimental variables. Regarding elicitation, we opted for the telling mode, since the children that have participated in the current study were 5- to 11-years-old, and would therefore be able to cope with the planning and expressive language demands of telling a story without a model.

Children were also administered two language ability tasks that tapped into their expressive vocabulary and sentence repetition skills. The specific tasks allowed us to examine the extent to which group differences in reference use in the oral narrative task stemmed from the children's language ability, and more specifically, their vocabulary knowledge and their morpho-syntactic skills.

We formulated the following research questions and hypotheses: 
Question 1. What is the effect of DLD and the effect of typological distance between bilingual children's L1 and L2 on the appropriateness of their referring expressions in the maintenance function?

Hypothesis 1. Based on Tsimpli et al.'s (2016a) finding that bilingualism improves DLD children's ability to choose referentially appropriate expressions in their narratives, we hypothesized that bilingual children with DLD would not differ from their TD bilingual peers on the proportions of referentially appropriate expressions. In fact, we did not expect referential appropriateness to vary as a function of the typological distance between the children's L1 and L2/Greek, since efficiency at tracking discourse referents and mapping them onto referential forms mainly depends on global contextual constraints and children's cognitive abilities, such as working memory, which have been found to be boosted by bilingualism in both TD and DLD populations (Tsimpli et al., 2016b; Peristeri, Baldimtsi, Tsimpli, \& Durrleman, 2019).

Question 2. What is the effect of DLD and the effect of the typological distance between bilingual children's L1 and L2 on grammatical correctness of referring expressions in the maintenance function?

Hypothesis 2. We hypothesized that the type of grammatical errors of Russian-Greek and Albanian-Greek children with DLD would reflect cross-linguistic influence from the children's L1. As such, we expected Russian-Greek children with DLD to exhibit higher rates of grammatical errors (e.g. more article-drops or clitic drops in object position) than their Albanian-Greek peers with DLD due to the difference between Russian and Greek in terms of their referential systems. Finally, we hypothesized that both bilingual groups with DLD would commit more grammatical errors than TD bilingual children, with the strength of grammatical violations being modulated by DLD children's language ability level.

\section{Method}

Participants

Four groups of children participated in the study: twenty-five Albanian-Greek bilingual children with DLD, twenty-five Russian-Greek bilingual children with DLD, and fifty agematched TD bilingual children, half Albanian-Greek and the rest Russian-Greek bilinguals. Prior to data collection, the bilingual children with DLD were administered the Greek version of the WISC-III (Wechsler, 1992; adapted in Greek by Georgas, Paraskevopoulos, Besevegis, Giannitsas, \& Mylonas, 2003). The children with DLD had a performance IQ (PIQ) of 90 or above, while verbal IQ was at least 2 standard deviations below age level (Bloom \& Lahey, 1978). Table 1 below shows information of the participants' age, PIQ and biodata calculated from the parental questionnaire. The four groups did not significantly differ in age, $F(3,99)=$ $0.018, p=.997$, or in PIQ scores, $F(3,99)=1.664, p=.200$. 
[Table 1 about here]

The children's bilingual status was assessed through a parental questionnaire, which was administered in Greek (Mattheoudakis, Chatzidaki, Maligkoudi, \& Agathopoulou, 2016). The bilingual children came from mixed marriages, thus we are dealing with simultaneous bilinguals who up to the age of 3 had exposure to both languages. The main questions of the parental questionnaire were grouped in two categories: (a) home language history and (b) current language use (see Andreou, 2015 for more details). Home language history refers to exposure to each language from birth up to the age of schooling (i.e. up to the age of six). Current language use refers to the language preferences for daily activities, oral interaction with family members and friends, and the language that they feel they understand or speak better. It should be noted that Table 1 presents the questionnaire's results (\%) for exposure to Greek, whereas the remainder corresponds to input in Albanian or Russian. The results from the questionnaires revealed that with respect to home language history no differences were detected among the four groups $(p>.10)$. On the other hand, the four groups differed with respect to current language use in $\operatorname{Greek}(F(3,96)=7.254, p=.020)$. Post-hoc (Tukey) tests have shown that the Russian-Greek TD and DLD groups used less Greek in their everyday activities than the Albanian-Greek TD $(p=.025$ and $p=.020)$ and the Albanian-Greek DLD children $(p=.029$ and $p=.027$, respectively).

The children with DLD were recruited from a diagnostic center in central Greece. They had a speech therapist's diagnosis of expressive and receptive DLD in the absence of any hearing loss, obvious neurological dysfunctions or motor deficits. None of them had received speech and language therapy before inclusion in the study. Teachers' reports and parental questionnaires confirmed significant delays in language development regarding each child's early language milestones (Leonard, 1998).

\section{Materials and procedure}

The four groups of children completed two language ability screening tests and the oral narrative task in a single session, and in a fixed order: expressive vocabulary, sentence repetition, and the oral narrative task. Narratives were elicited in Greek.

Language ability screening tasks

The bilingual children's lexical and morpho-syntactic abilities in Greek were tested through an expressive vocabulary and a sentence repetition task.

Expressive Vocabulary Task (Vogindroukas, Protopapas, \& Sideridis, 2009; adaptation from Renfrew, 1997). The children's expressive vocabulary in Modern Greek was assessed with an 
expressive vocabulary test, which has been standardized for 3- to 10-year-old Greek-speaking monolingual children. It includes 50 black-and-white pictures of common objects that each child was asked to name individually. Each correct answer earned one point, with a maximum score of 50. The test was terminated in case the participant failed to respond correctly to five consecutive trials.

Sentence Repetition Task. The sentence repetition task was developed within the COST Action IS0804 (Marinis \& Armon-Lotem, 2015). The Greek version (Chondrogianni, Andreou, Peristeri, Tsimpli, Varlokosta \& Neratzini, 2013) of the task includes 32 sentences distributed over 8 sets of syntactic structures of varying complexity; namely, Subject-Verb-Object sentences, sentences containing factual and non-factual negation, structures with clitics in clitic left dislocation and clitic doubling contexts, complement clauses, coordinated sentences, adverbial clauses, referential and non-referential object wh-questions, and subject and object relative clauses. All sentences across the eight different structures were matched for length and word frequency. During the task the child listened to each sentence only once and repeated it as accurately as possible. Any mistake in the repetition of a word or any omitted word was counted as an error. There was a practice session, so that the participant became familiar with the procedure. Each child listened to the sentences via headphones and her/his responses were recorded. Regarding scoring, the child scored three points for each sentence repeated correctly, while two points and a single point were awarded in case s/he made one and two errors, respectively. In case the child made more than two errors while repeating a single sentence, $\mathrm{s} /$ he received zero points. The highest possible score was 96 points.

\section{Narrative task and coding scheme for referent maintenance}

The narrative task was administered to all TD and DLD children. The children's narratives were elicited in the telling mode with two stories (namely, 'Cat' and 'Dog'). The assignment of the two stories was counterbalanced across children. Thirteen of the children in the TD RussianGreek and the Albanian-Greek DLD group were asked to tell the Cat story, and the rest were asked to tell the Dog story. Likewise, 13 children in the TD Albanian-Greek and DLD RussianGreek group were assigned the Cat story and the rest the Dog story.

Procedure. Data collection took place over a period of seven months. Each child with DLD was tested individually either at the diagnostic center or at her/his home, while the TD children were tested at school in a quiet room.

All children were assigned a computerized version of the story. Each session started with the child sitting in front of a portable computer and next to a female adult that was blind to the purpose of the study. The child was shown three coloured envelopes on the computer screen and was asked to open one of them; all three envelopes included the same story. The 
(8) Null pronoun in subject position

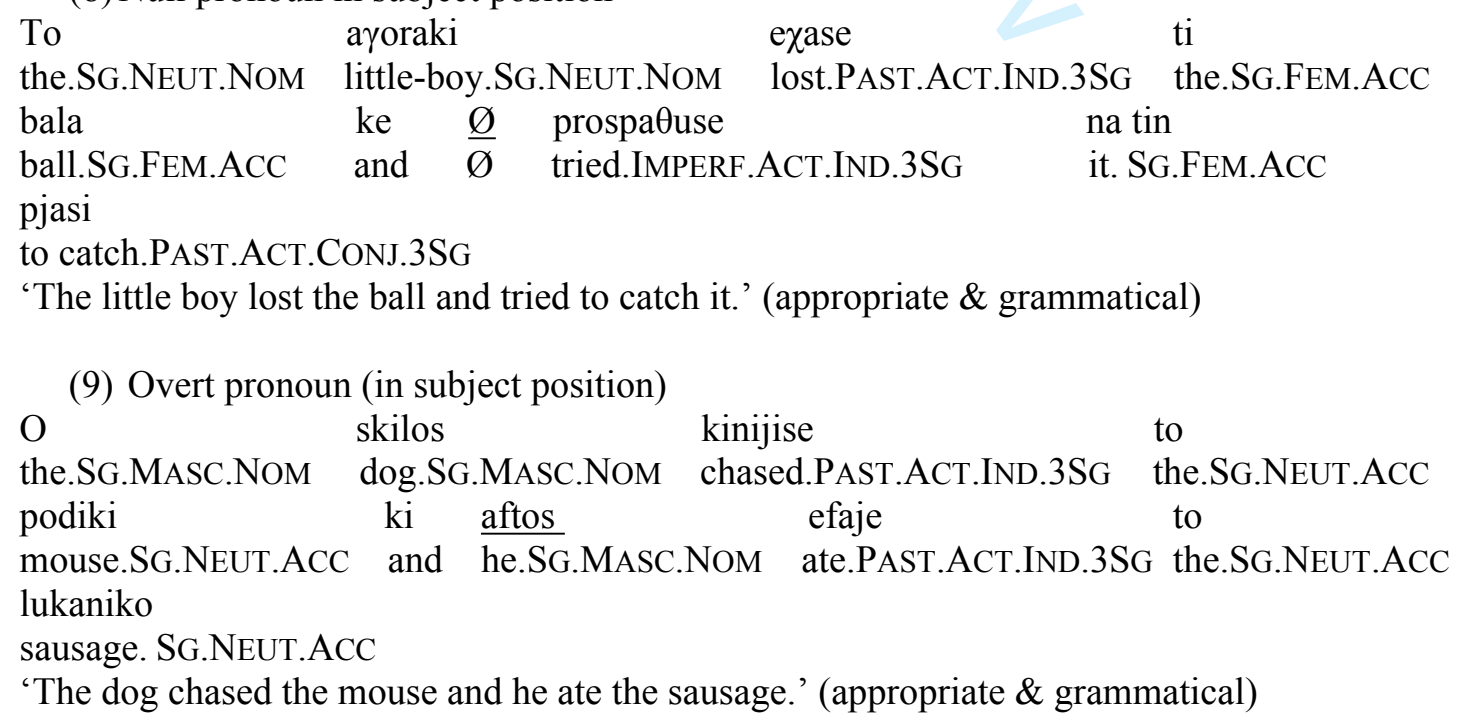


I yata ide to the.SG.FEM.NOM cat.SG.FEM.NOM saw.PAST.ACT.IND.3SG the.SG.NEUT.ACC ayoraki ke to $\underline{\text { ayoraki }}$ little-boy.SG.NeUT.ACC and the.SG.NEUT.NOM little-boy.SG.NEUT.NOM tromakse got scared.PAST.ACT.IND.3SG

'The cat saw the little boy and the little boy got scared.' (appropriate \& grammatical)

(11) Pronominal clitic

O skilos prosekse ena the.SG.MASC.NOM dog.SG.MASC.NOM noticed.PAST.ACT.IND.3SG a.SG.NEUT.ACC podiki ke pioikse psila na to mouse.SG.NEUT.ACC and jumped.PAST.ACT.IND.3SG high to it.SG.NEUT.ACC ftasi reach.PAST.ACT.CONJ.3SG

'The dog noticed a mouse and jumped high to reach it.' (appropriate \& grammatical)

(12) Article-drop

O skilos vlepi ena the.SG.MASC.NOM dog.SG.MASC.NOM sees.PRES.ACT.IND.3SG a.SG.NeUT.ACC

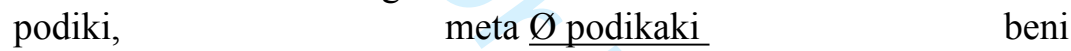
little-mouse.SG.NEUT.ACC, then $\varnothing$ little-mouse.SG.NEUT.NOM gets.PRES.ACT.IND.3SG sto $\quad$ Sedro in-the.SG.NEUT.ACC tree.SG.NEUT.ACC

'The dog sees a little mouse, then (the) little mouse gets into the tree.' (appropriate \& grammatical)

(13) Indefinite NP

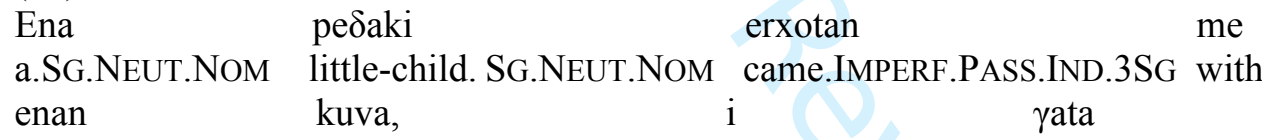
a.SG.MASC.ACC bucket.SG.MASC.ACC, the.SG.FEM.NOM cat.SG.FEM.NOM scared. tromakse $\underline{\text { ena }} \underline{\text { ayoraki }}$ scared.PAST.ACT.IND.3SG a.SG.NEUT.ACC little-boy.SG.NEUT.ACC 'A little child was coming with a bucket, the cat scared a little boy.' (appropriate \& grammatical)

We also distinguished between grammatical and ungrammatical expressions, irrespective of their referential appropriateness. Ungrammatical expressions consisted of article-drops in NPs, substitution errors (i.e. wrong use of person/case/number/gender feature) on overt pronouns and pronominal clitics, and null pronouns in obligatory object contexts (see underlined phrases in examples 14-17). It should be clarified that article-drops in NPs were treated as ungrammatical expressions (see underlined phrase in example 14).

(14) Article-drop in NPs

\begin{tabular}{|c|c|c|}
\hline $\begin{array}{l}\text { O } \\
\text { the.SG.MASC.NOM } \\
\text { podiki, } \\
\text { mouse.SG.NEUT.ACC, } \\
\text { sto }\end{array}$ & $\begin{array}{ll}\text { skilos } & \text { vlepi } \\
\text { dog.SG.MASC.NOM sees.PRES.ACT.IND.3SG } \\
\text { meta } \varnothing \text { podikaki } & \text { beni } \\
\text { then } \emptyset \text { little-mouse.SG.NEUT.NOM } & \text { gets.Pr } \\
\text { dedro } & \end{array}$ & $\begin{array}{l}\text { ena } \\
\text { a.SG.NEUT.ACC } \\
\text { ES.ACT.IND.3SG }\end{array}$ \\
\hline
\end{tabular}

in-the.SG.NEUT.ACC tree.SG.NEUT.ACC

'The dog sees a mouse, then (the) little-mouse gets in the tree'. (appropriate, ungrammatical) 
Substitution errors on overt pronouns

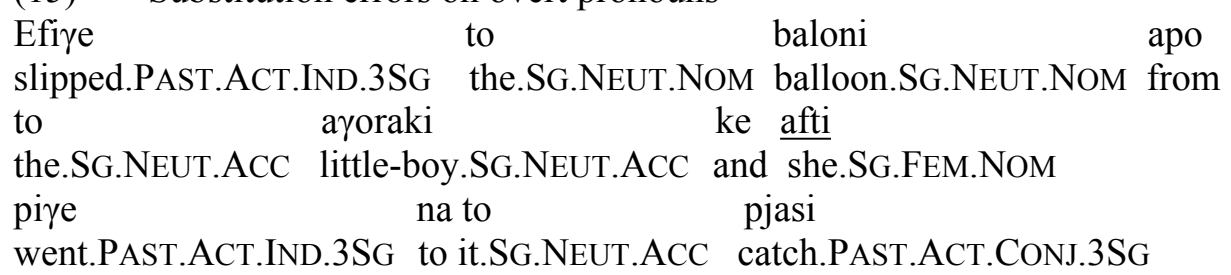

'The balloon slipped from the little boy's hand and she went to catch it'. (appropriate, ungrammatical)

(16) Substitution errors on pronominal clitics

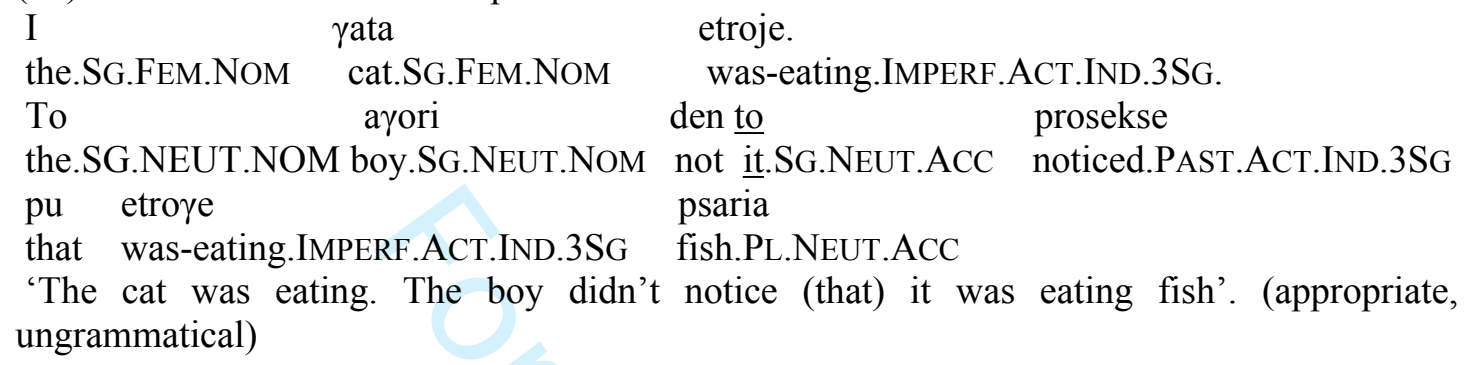

The transcribed narrative samples were independently coded for reference by the first two authors. The output was then checked to identify instances of inconsistencies, omissions, or double coding. Collapsing over type of referential expression, the percentage agreement mean for coding was $89.4 \%$. Differences in reference coding were discussed among the three authors, changes were made where necessary, and the adjusted coding was used for the statistical analyses.

\section{Analysis Plan}

First, two First Language (L1) x Disorder (2 x 2) factorial between-subject analyses of variance (ANOVA) were performed for the language ability tests, one for expressive vocabulary and one for sentence repetition (L1 levels: Russian, Albanian; Disorder levels: DLD, TD).

The next set of analyses aimed at controlling for potential confounding effects of story type and narrative length, which could have affected the patterns of referential forms in the children's narratives. Regarding narrative length, children with DLD often produce shorter narrations than TD children (Heilmann, Miller, Nockerts, \& Dunaway, 2010; Mäkinen, 2014; Pearce, James, \& McCormack, 2009). We thus ran one-way ANOVA analyses to investigate 
differences in narrative length across the four experimental groups. Regarding story type, as already mentioned, both Cat and Dog stories were used in the current study, and the story assigned to the children in each group was counterbalanced. To avoid story biases, chi-square tests were run comparing raw numbers of referring expressions between the two stories (Cat/Dog) in each of the four groups.

Using the coding scheme (see 'Transcription and coding'), we calculated percentages of referentially appropriate vs inappropriate forms. The percentages were taken from the total number of referring expressions produced by each group. The same procedure was followed for grammatical vs ungrammatical referring expressions.

Next, in order to investigate possible L1 and Disorder effects, as well as L1 x Disorder interaction effects, on the referential forms in the children's narratives, logit mixed effects models were performed, one for referentially appropriate vs inappropriate expressions, and one for grammatical vs ungrammatical expressions. Disorder (DLD, TD) and L1 (Russian, Albanian) were the predictors in each model, while participants were the random slopes. Age was also included as a predictor in all models. Logit mixed effects models were also performed for each type of referentially appropriate, inappropriate and ungrammatical expression. The models were fitted in $\mathrm{R}$ using the lmer function from the lme4 package (Bates \& Maechler, 2009).

As a final step, to examine possible interactions between the children's bilingual status, their performance in the language ability tests and their use of referring expressions, partial correlation analyses were performed, after controlling for the children's age. Two correlation analyses were performed, one for referentially appropriate expressions, and one for grammatical expressions. Bilingualism status was operationalized as the children's home language history and current language use (of Greek) (see 'Participants'), and language was measured through the children's expressive vocabulary and sentence repetition scores (see 'Materials and procedure').

\section{Results}

\section{Language Ability Screening Tasks}

Table 2 below presents the groups' mean scores on expressive vocabulary and sentence repetition.

[Table 2 about here]

The $2 \times 2$ factorial ANOVA analyses showed a significant effect of Disorder for both language ability tests (expressive vocabulary: $F(1,99)=4.734, p=.032, \eta^{2}=.05$; sentence 
repetition: $\left.F(1,99)=6.842, p=.010, \eta^{2}=.07\right)$, indicating that both Albanian-Greek and Russian-Greek groups with DLD scored significantly lower than their TD peers. There was also a significant effect of $\mathrm{L} 1$ (expressive vocabulary: $F(1,99)=20.122, p<.001, \eta^{2}=.17$; sentence repetition: $\left.F(1,99)=29.777, p<.001, \eta^{2}=.24\right)$, which stemmed from the fact that RussianGreek children scored significantly lower than Albanian-Greek children on both tests. The Disorder x L1 interaction effect was not significant for either expressive vocabulary $(F(1,99)$ $\left.=.098, p=.755, \eta^{2}=.01\right)$, or sentence repetition $\left(F(1,99)=.514, p=.475, \eta^{2}=.01\right)$.

\section{Disorder and L1 effects on referring expressions}

This section first presents the distribution of the referring expressions, which were used by Albanian-Greek and Russian-Greek children with and without DLD, and then the output of the analyses that focused on the effect of Disorder and L1 on the referential appropriateness and grammatical correctness of the expressions. Results are reported for referent maintenance only.

The total number of referring expressions that the children produced in their narratives was 871. Figure 1 below presents the raw numbers by type of referential expression and experimental group. A different pattern was observed for the two language pairs. In particular, Albanian-Greek TD and DLD children seem to use null pronouns and clitics to a greater extent than Russian-Greek TD and DLD children. On the other hand, the latter group tended to use definite DPs.

\section{[Figure 1 about here]}

To rule out the possibility that there was an effect of narrative length on the children's referring expressions, narrative length was measured in terms of verb clauses (Mean: 15.8 (SD: 5.1) for TD Albanian-Greek children; Mean: 14.1 (SD: 5.9) for TD Russian-Greek children; Mean: 14.6 (SD: 5.6) for Albanian-Greek children with DLD; and Mean: 14.3 (SD: 5.1) for Russian-Greek children with DLD). There was no significant group effect in narrative length, $F(3,96)=1.934, p=.129$. Similarly for story type, there were no significant differences in the number of referring expressions between the Cat and the Dog story for either experimental group $\left(\chi^{2}(1, N=42)=.407, p=.151\right.$ for TD Albanian-Greek children; $\chi^{2}(1, N=42)=.386, p$ $=.160$ for TD Russian-Greek children; $\mathrm{x}^{2}(1, N=36)=.247, p=.100$ for Albanian-Greek children with DLD; and $\chi^{2}(1, N=36)=.248, p=.213$ for Russian-Greek children with DLD).

\section{Referentially appropriate vs inappropriate expressions}

We first analyzed the effect of Disorder (DLD, TD) and L1 (Russian, Albanian) on children's referentially appropriate vs inappropriate expressions. The percentages of appropriate referring expressions were $99.3 \%, 96.6 \%, 97.6 \%$ and $96.9 \%$ for TD Albanian-Greek children, TD Russian-Greek children, Albanian-Greek children with DLD, and Russian-Greek children with 
DLD, respectively. Table 3 below presents the distribution of the percentages of referentially appropriate (i.e. null and overt pronouns in subject position, overt pronouns in object position, definite NPs, pronominal clitics and article-less NPs) and inappropriate expressions (i.e. indefinite NPs) by type and experimental group.

The final mixed effects model in Table 4 showed a significant effect of age, yet, nonsignificant effects of Disorder or L1. There was no significant interaction between Disorder and L1.

[Table 3 about here]

[Table 4 about here]

\section{Types of appropriate and inappropriate expressions}

Percentages of appropriate and inappropriate expressions were split by type (i.e. definite and indefinite NPs, null and overt pronouns in subject position, overt pronouns in object position, pronominal clitics and article-less NPs) and further analyses were performed on each type.

Table 5 presents the results of the mixed effects models. There was a significant effect of Disorder for the model on article drops, as well as a significant effect of L1 in the model on definite NPs, article drops, null subject pronouns and clitics. Also, there was a significant effect of age on definite NPs, article drops, null and overt subject pronouns.

[Table 5 about here]

\section{Grammatical vs ungrammatical expressions}

We next investigated the effect of Disorder (DLD, TD) and L1 (Russian, Albanian) on children's grammatical vs ungrammatical expressions. Table 6 below presents the distribution of percentages of grammatical and ungrammatical expressions by type and experimental group.

The mixed effects model showed significant main effects of Disorder and L1, as well as a significant interaction between Disorder and L1. The Russian-Greek group with DLD produced fewer grammatical referring expressions than their Albanian-Greek peers with DLD $(59.21 \%<89.27$; Estimate $=3.13, S E=2.56, t=1.57, p<.001)$. The age effect was not found to be significant (see Table 7).

[Table 6 about here]

[Table 7 about here]

\section{Types of ungrammatical expressions}


Exploring the links between children's bilingual status and language ability, and appropriateness and grammatical accuracy

Table 9 displays the results of the partial correlation analyses that focused on the exploration of possible associations between children's bilingual status and language ability, and the appropriateness and grammatical accuracy of their referring expressions, while controlling for children's age. The results of the partial correlation analyses showed that the use of appropriate referring expressions was positively associated with expressive vocabulary for the TD Albanian-Greek group, and with current language use for both Albanian-Greek groups. No other significant correlation emerged.

[Table 9 about here]

\section{Discussion}

The current study set out to contribute to the investigation of referring expressions while maintaining characters in the oral narratives of 5- to 11-year-old bilingual Albanian-Greek and Russian-Greek children with DLD, along with age-matched TD bilingual children speaking the same language pairs. Our main objective was to integrate language impairment and L1 transfer effects (or possible interactions between the two) into an explanation of DLD children's production of D elements, by comparing reference use across TD children and children with DLD, and by manipulating the typological distance in the children's language pairs: AlbanianGreek, which have similar D systems, and Russian-Greek, which have distinct D systems since Russian lacks a definiteness distinction and allows null objects with specific reference. Referring expressions in the present study were coded along two dimensions: referential appropriateness irrespective of their grammatical well-formedness, and grammatical 
correctness irrespective of the expressions' referential appropriateness. The results showed that the four groups did not differ in their overall rates of referentially (in)appropriate expressions; yet, Russian-Greek children tended to use fewer non-lexically specified expressions, such as null subject pronouns and clitics, to maintain reference to the story characters in comparison to Albanian-Greek children who produced more definite NPs. Moreover, both groups with DLD committed more grammatical errors in their referring expressions than their TD peers; article drops and null pronouns in object position characterized the referring expressions of children with DLD. Crucially, Russian-Greek children with DLD produced significantly more null pronouns in obligatory object contexts than Albanian-Greek bilinguals with DLD. These patterns of performance imply that reference use in bilingual children with DLD was jointly influenced by language impairment and L1 typological properties. Moreover, while the use of appropriate referring expressions was found to increase with age, there was no significant age effect on the use of grammatical expressions.

The first research question of the study was to investigate whether the groups would differ in their rates of referentially (in)appropriate expressions. The lack of a significant group effect in the use of inappropriate expressions (i.e. indefinite NPs) implies that language impairment (and/or L1 properties) did not affect children's referential choices at the discourse level. It seems that children with DLD were sensitive to the availability of the story characters in preceding discourse and this increased the likelihood of maintaining them in subsequent discourse through appropriate referring expressions. This finding is in line with past research (Tsimpli et al., 2016a) that found no deficit in a group of 9-year-old bilingual Albanian-Greek DLD children's ability to produce referentially appropriate expressions in a narrative task. Additionally, Gagarina (2012) found that 4- and 5-year-old early Russian-German sequential bilingual children showed higher rates of anaphoric personal pronouns relative to their Russianspeaking monolinguals peers in elicited narratives. The results of the current study indicate that children with DLD were not disadvantaged in their skills to establish coherence relations between the events of the story through referential devices, which is further corroborated by the fact that they did not fall behind their TD bilingual peers in the number of referring expressions that they used in their narratives (see Figure 1).

Though children with DLD did not differ from TD children in their ability to use referentially appropriate forms, type of L1 seemed to affect children's preferences for certain expressions. More specifically, Russian-Greek children tended to use higher proportions of definite NPs relative to their Albanian-Greek peers who preferred to use null subject pronouns and clitics instead. We hypothesize that the difference between Albanian-Greek and RussianGreek groups was driven by the L1 effect. In particular, Albanian-Greek TD and DLD groups seemed to benefit from the typological proximity of Greek and Albanian D systems which led to cross-language transfer and, thus, to high proportions of null pronouns and clitics. 
Furthermore, several studies have noted that bilinguals speaking a null-subject/non-null-subject language combination tend to produce overt pronouns or DPs in contexts, in which the use of a null pronoun or a clitic would have been more appropriate (i.e., when maintaining reference to a discourse referent) (Belletti, Bennati, \& Sorace, 2007; Serratrice, Sorace, \& Paoli, 2004; Tsimpli et al., 2004). This could also be the case with our Russian-Greek groups, since Russian is considered to be a partial pro-drop language. An alternative explanation for Russian-Greek children's low pronominalisation rates relative to their Albanian-Greek peers may be that the former group found the structure of the Greek D-system hard and resource-demanding, especially since Russian and Greek are typologically distinct languages with respect to their referential systems. Similarly, Gagarina (2008) found that sequential Russian-German TD bilingual children tended to pronominalize story characters (in the Maintenance function) considerably less in German as the second language than simultaneous Russian-German TD bilingual children, which has been attributed to L1 effects or/and cognitive processing reasons. In the current study, the correlational analyses revealed that Albanian-Greek children's use of referentially appropriate forms correlated positively with their current language use in Greek. This finding is in line with Andreou, Torregrossa, \& Bongartz's (in press) narrative study that examined the production of null subjects in Greek-Italian bilingual children. Bilingual children in Andreou et al.'s (in press) study exhibited extensive use of null subject pronouns in Italian and this effect was modulated by language dominance, which was measured through current language and literacy activities. Similarly, Torregrossa, Andreou, Bongartz and Tsimpli's (in press) study has examined the use of under-informative and over-informative referring expressions in Greek with bilingual children speaking three different language pairs, namely, Greek-Albanian, Greek-English, and Greek-German. Their study revealed that language experience and proficiency in the non-target language (i.e. Albanian, English, German) accounted for variance in the number of over-specified expressions, independently of whether the other language spoken was a null-subject language (such as Albanian) or a non-null-subject one (such as English and German).

Besides the greater use of definite NPs by Russian-Greek children compared to their Albanian-Greek peers, Russian-Greek participants were found to use more article-less NPs than Albanian-Greek groups. This pattern of performance reflects L1 transfer effects that stem from the lack of a D system in the Russian language. Russian-Greek children in the present study might have faced more challenges in morpho-syntactically computing well-formed nominal phrases that do not exist in their L1. Tsimpli's (2003) study has also highlighted L1 transfer effects on the production of D elements in healthy, late bilingual adults with Russian L1 and Greek L2 adults. L1 transfer effects in her study were mainly evident in adults' deficient production of definite determiners and 3rd person clitics in Greek. Tsimpli (2003) suggested that Russian adult learners could not acquire novel syntactic features in their L2/Greek due to 
maturational constraints and the fact that the specific features lacked interpretability at LF (Tsimpli \& Dimitrakopoulou, 2007).

The second research question of the study was to investigate language impairment and L1 transfer effects in the grammatical correctness of the children's referring expressions irrespective of the latter's referential appropriateness. The overall pattern of children's performance reveals a strong language impairment effect, since both groups with DLD produced significantly more grammatical errors in their referring expressions than their TD peers. Crucially, both Russian-Greek groups tended to drop the articles in NPs to a considerably greater extent than Albanian-Greek groups. This pattern implies that article drop was driven by L1 transfer effects, given that object-drop is possible in both Greek (in nonreferential/indefinite contexts only; Tsimpli \& Papadopoulou, 2009) and Russian, as opposed to Albanian. Also, Russian-Greek children with DLD produced significantly more null pronouns in obligatory object contexts which further suggests that the L1 transfer effect was accentuated by the children's language impairment.

Though the production of null pronouns in obligatory object contexts seemed to differentiate the two groups with DLD, substitution errors on clitics (and overt pronouns) did not significantly differ among groups. In fact, clitic substitution errors were very few in each group, which suggests that clitic production in oral narrative performance incurred a far smaller penalty than other referential forms. Though the specific finding is not surprising for TD children, it is rather unexpected for children with DLD for whom the morpho-syntactic realization of object clitics has been reported to be highly vulnerable cross-linguistically (Arosio et al., 2010; Chondrogianni, Marinis, Edwards, \& Blom, 2015; Jakobson \& Schwartz, 2002; Jakubowicz et al., 1998; Tsimpli et al., 2013). Assuming that processing difficulty contributes to performance variation in clitic production tasks, the specific result aligns with the hypothesis that the reduced rates of clitic substitution errors in the two groups with DLD of the current study is due to the narrative task and the fact that the story's contextual strength influenced the computation of clitics for the language-impaired children. More specifically, we hypothesize that children with DLD in the current study were more able to rapidly integrate visual contextual cues, including the sequencing of the pictures and the visually presented actions and story characters, to produce grammatically correct referent-clitic pronoun mappings in their oral narratives. The specific finding seems to agree with Tsimpli and colleagues' (2017) study which has shown that Albanian-Greek children with DLD achieved higher levels of grammatical correctness in clitic production in an oral narrative compared to a clitic elicitation task.

Interestingly, children with DLD showed deficits in the grammatical use of referring expressions compared to TD children, while this deficit was not found to attenuate with chronological age. On the other hand, though the four experimental groups did not differ in 
terms of the proportions of appropriate referring expressions, this skill was found to become better with age. Our results are consistent with existing studies reporting that children with DLD are challenged by the structural demands of having to compute referring expressions rather than by a pragmatic difficulty (Davies, Andrés-Roqueta, \& Norbury, 2016; ReuterskiöldWagner, Nettelbladt, \& Sahlén, 2001). This finding provides support for the grammatical (vs. pragmatic) deficit as a key factor associated with the production of referring expressions in DLD.

\section{Conclusions}

In the present study, we investigated the referential appropriateness and grammatical correctness of the referring expressions in the oral narratives of bilingual children with and without DLD. To the best of our knowledge, this is the first study to address bilingual DLD children's reference use in elicited narration through the lens of L1-specific effects. Critically, the language pairs of the bilingual groups (i.e. Russian-Greek \& Albanian-Greek) differed typologically in terms of their D system. The findings show that language impairment did not negatively affect children's ability to choose referentially appropriate forms. Regarding grammatical correctness, children with DLD tended to make more errors on their referring expressions, while Russian-Greek bilinguals with DLD exhibited high article drop rates and considerably higher rates of null pronouns in obligatory object contexts even than their Albanian-Greek peers with DLD. The overall findings show that, besides language impairment, reference use in bilingual children with DLD is strongly modulated by L1 transfer effects, which should be taken into careful consideration in future studies that focus on bilingualism effects in the referential abilities of children with DLD.

\section{Acknowledgements}

We would like to thank the children and their parents for their participation in the study.

\section{Author contributions}

The authors declare equal contribution.

\section{Funding}

The authors received no financial support for the research, authorship, and/or publication of this article. 


\section{References}

Andreou, M. (2015). The effects of bilingualism in verbal and non verbal cognition: The microand macro-structure of narratives in the weak and the dominant language of the bilingual child. Auth: Unpublished PhD Thesis.

Andreou, M., Torregrossa, J., \& Bongartz, C. (in press). The use of null subjects by GreekItalian bilingual children: Identifying cross-linguistic effects. In G. Fotiadou \& I. M. Tsimpli (Eds.), Individual differences in anaphora resolution: Language and cognitive effects. Amsterdam: John Benjamins.

Andreou, M., Tsimpli, I. M., Kananaj, A., \& Kapia, E. (2016). Narrative insights from 6 - 7 year old Greek-Albanian Children. In M. Mattheoudakis \& K. Nicolaidou (Eds.), Selected Papers from the $21^{\text {st }}$ International Symposium of Theoretical and Applied Linguistics (ISTAL) (pp. 67-82). Thessaloniki: School of English, Aristotle University of Thessaloniki.

Arosio, F., Branchini, C., Forgiarini, M., Roncaglione, E., Carravieri, E., Tenca, E., \& Guasti, M. T. (2010). SLI children's weakness in morphosyntax and pragmatics. In O. Yukio (Eds.), Proceedings of the Tenth Tokyo Conference on Psycholinguistics (pp. 57-75). Tokyo: Hituzi Syobo Press.

Bailyn, J. F. (1995). A Configurational Approach to Russian "free" Word Order. Ph.D. thesis, Cornell University, Ithaca, NY.

Bates, D., \& Maechler, M. (2009). lme4: Linear mixed-effects models using S4 classes. R package version 0.999375-32.

Bedore, L., \& Leonard, L. (2001). Grammatical morphology deficits in Spanish-speaking children with specific language impairment. Journal of Speech, Language, and Hearing Research, 44, 905-924.

Belletti, A., Bennati, E., \& Sorace, A. (2007). Theoretical and developmental issues in the syntax of subjects: Evidence from near-native Italian. Natural Language \& Linguistic Theory, 25, 657-689.

Bishop, D., \& Donlan, C. (2005). The role of syntax in encoding and recall of pictorial narratives: Evidence from specific language impairment. British Journal of Developmental Psychology, 23 (1), 25-46.

Blom, E., Vasić, N., \& Baker, A. (2015). The pragmatics of articles in Dutch children with specific language impairment. Lingua, 155, 29-42.

Bloom, L., \& Lahey, M. (1978). Language development and language disorders. New York: Wiley.

Bottari, P., Cipriani, P., Chilosi, A. M., \& Pfanner, L. (2001). The Italian determiner system in normal acquisition, specific language impairment, and childhood aphasia. Brain and Language, 77 (3), 283-293. 
Carminati, M. N. (2002). The processing of Italian subject pronouns. Unpublished doctoral dissertation, University of Massachusetts at Amherst.

Chondrogianni, V., Andreou, M., Nerantzini, M., Varlokosta, S., \& Tsimpli, I. M. 2013. The Greek Sentence Repetition Task. COST Action IS0804.

Chondrogianni, V., \& Marinis, T. (2015). Production of definite and indefinite articles in typically developing English-speaking children and children with SLI. Lingua, 155, 928.

Chondrogianni, V., Marinis, T., Edwards, S., \& Blom, E. (2015). Production and on-line comprehension of definite articles and clitic pronouns by Greek sequential bilingual children and monolingual children with specific language impairment. Applied Psycholinguistics, 36 (5), 1155-1191.

Colozzo, P., \& Whitely, C. (2014). Keeping track of characters: Factors affecting referential adequacy in children's narratives. First Language, 34, 155-177.

Dahl, Ö. (1970). Some Notes on Indefinites. Language, 46, 33-41.

Davies, C., Andrés-Roqueta, C., \& Norbury, C. F. (2016). Referring expressions and structural language abilities in children with specific language impairment: A pragmatic tolerance account. Journal of Experimental Child Psychology, 144, 98-113.

De La Mora, J., Paradis, J., Grinstead, J., Flores, B., \& Cantu, M. (2004). The production of object clitics in Mexican Spanish-speaking children, with and without SLI. Poster presented at the Symposium for Research on Child Language Disorders, University of Wisconsin, Madison, USA.

De Weck, G., \& Jullien, S. (2013). How Do French-Speaking Children with Specific Language Impairment First Mention a Referent in Storytelling? Between Reference and Grammar. Journal of Pragmatics, 56, 70-87.

Dimitriadis, A. (1994). Clitics and object drop in Modern Greek. In C. Giordano, \& D. Ardron (Eds.), Proceedings of the Sixth Student Conference in Linguistics (SCIL-6) (pp. 1-20). University of Rochester, New York, USA.

Engel de Abreu, P. M., Cruz-Santos, A., \& Puglisi, M. L. (2014). Specific language impairment in language-minority children from low-income families. International Journal of Language and Communication Disorders, 49(6), 736-747.

Franks, S. (1995). Parameters of Slavic morphosyntax. Oxford: Oxford University Press.

Franks, S., \& King, T. H. (2000). A handbook of Slavic clitics. Oxford: Oxford University Press.

Gagarina, N. (2008). Anaphoric pronominal reference in Russian and German narratives: Bilingual and monolingual settings. Zeitschrift für Slawistik, 53(3), 326-338.

Gagarina, N. (2012). Discourse cohesion in the elicited narratives of early Russian-German sequential bilinguals. In K. Braunmüller \& C. Gabriel (Eds.), Multilingual individuals and multilingual societies (pp. 101-119). Amsterdam: John Benjamins. 
Gagarina, N., Klop, D., Bohnacker, U., Kunnari, S., Tantele, K., Välimaa, T., Balčiūnienė, I. \& Walters, J. (2012). Multilingual Assessment Instrument for Narratives (MAIN). ZAS Papers in Linguistics 56. Berlin: Zentrum für Allgemeine Sprachwissenschaft.

Georgas, J., Paraskevopoulos, I. N., Besevegis, E., Giannitsas, N., \& Mylonas, K. (2003). Greece. In J. Georgas, L. G. Weiss, F. J. R. van de Vijver, \& D. H. Saklofske (Eds.), Culture and Children's Intelligence: Cross-cultural analysis of the WISC-III (pp. 199214). San-Diego, CA: Academic Press.

Gordishevsky, G., \& Avrutin, A. (2003). Subject and object omissions in child Russian. Online Proceedings of IATL 19. Retrieved from http://atar.mscc.huji.ac.il/ english/IATL/19/

Gülzow, I., \& Gagarina, N. (2007). Noun phrases, pronouns and anaphoric reference in young children narratives. ZAS Papers in Linguistics, 48, 203-223.

Hansson, K., Nettelbladt, U., \& Leonard, L. B. (2003). Indefinite articles and definite forms in Swedish children with Specific Language Impairment. First Language, 23(3), 343-362. Haspelmath, M. (1997). Indefinite Pronouns. Oxford: Oxford University Press.

Heilmann, J., Miller, J. F., Nockerts, A., \& Dunaway, C. (2010). Properties of the narrative scoring scheme using narrative retells in young school-age children. American Journal of Speech-Language Pathology, 19, 154-166.

Ioup, G. (1977). Specificity and the interpretation of quantifiers. Linguistics and Philosophy, 1, 233-245.

Jakobson, P., \& Schwartz, R.G. (2002). Morphology in incipient bilingual Spanish-speaking preschool children with specific language impairment. Applied Psycholinguistics, 23, $23-41$.

Jakubowicz, C., Nash, L., Rigaut, C., \& Gerard, C. L. (1998). Determiners and clitic pronouns in French-speaking children with SLI. Language Acquisition, 7, 113-160.

Laloi, A., de Jong, J., \& Baker, A. (2017). Can executive functioning contribute to the diagnosis of SLI in bilingual children? A study on response inhibition. Linguistic Approaches to Bilingualism, 7, 431-459.

Leonard, L. B. (1998). Children with Specific Language Impairment. Cambridge, MA: MIT Press.

Mäkinen, L. (2015). Narrative language in typically developing children, children with specific language impairment and children with autism spectrum disorder. $\mathrm{PhD}$ Thesis, Oulu: Oulu University, Series B124.

Marinis, T., \& Armon-Lotem, S. (2015). Sentence repetition. In S. Armon-Lotem, J. de Jong, \& N. Meir (Eds.), Assessing Multilingual Children: Disentangling Bilingualism from Language Impairment (pp. 95-124). Bristol: Multilingual Matters. 
Matthaioudakis, M., Chatzidaki, A., Maligkoudi, C., \& Agathopoulou, E. (2016). Family and school language input: Their role in bilingual children's vocabulary development. The Journal of Applied Linguistics, 31, 49-69.

McGregor, K. K., \& Leonard, L. B. (1994). Subject pronoun and article omissions in the speech of children with specific language impairment: A phonological interpretation. Journal of Speech \& Hearing Research, 37 (1), 171-181.

Miranda, A. E., McCabe, A., \& Bliss, L. S. (1998). Jumping around and leaving things out: a profile of the narrative abilities of children with specific language impairment. Applied Psycholinguistics, 19, 647-667.

Norbury, C. F., \& Bishop, D. V. M. (2003). Narrative Skills of Children with Communication Impairments. International Journal of Language and Communication Disorders, 38(3), 287-313.

Papadopoulou, D., Peristeri, E., Plemmenou, L., Marinis, T., \& Tsimpli, I.M. (2015). Pronoun ambiguity resolution: Evidence from monolingual adults and children. Lingua, 155, 98120.

Pearce, W. M., James, D. G. H., \& McCormack, P. F. (2010). A comparison of oral narratives in children with specific language and non-specific language impairment. Clinical Linguistics \& Phonetics, 24, 622-645.

Peristeri, E., Baldimtsi, E., Tsimpli, I. M., \& Durrleman, S. (2019). Bilingualism effects in children with Developmental Language Disorder: metalinguistic awareness, executive functions, and false-belief reasoning. In M. M. Brown, \& B. Dailey (Eds.), BUCLD 43: Proceedings of the 43rd annual Boston University Conference on Language Development (pp. 549-560). Boston, USA: Cascadilla Press.

Peristeri, E., \& Tsimpli, I. M. (in press). Reference use and attention shifting abilities in children with Autism Spectrum Disorders and Specific Language Impairment. To appear in C. Bongartz and J. Torregrossa (Eds.), What's in a narrative?. Somerville: Cascadilla Press.

Perlmutter, D., \& Moore, J. (2002). Language-Internal Explanation: The Distribution of Russian Impersonals. Language, 78, 619-650.

Renfrew, C. (1997). Word Finding Vocabulary Test (The Renfrew Language Scales). Oxford: Winslow Press.

Reuterskiöld-Wagner, C., Nettelbladt, U., \& Sahlén, B. (2001). Giving the crucial information: Performance on a referential communication task in Swedish children with language impairment. International Journal of Language \& Communication Disorders, 36, 433445 .

Schelletter, C., \& Leinonen, E. (2003). Normal and Language-Impaired Children's Use of Reference: Syntactic versus Pragmatic Processing. Clinical Linguistics and Phonetics, 17(4-5), 335-343. 
Serratrice, L., Sorace, A., \& Paoli, S. (2004). Crosslinguistic influence at the syntax-pragmatics interface: Subjects and objects in English-Italian bilingual and monolingual acquisition. Bilingualism: Language and cognition, 7(3), 183-205.

Sioupi, A. (2002). Bare NP in object position in Greek and their equivalence in German: an approach at the Syntax-Semantic Interface. In A. Anastasiadi-Symeonidi, \& M. Koutita -Kaimaki (Eds.), Studies in Greek Linguistics, Proceedings of the 22nd Annual Meeting of the Department of Linguistics (pp. 573-582). Thessaloniki: Kyriakidi.

Torregrossa, J. (2017). The role of executive functions in the acquisition of reference: The production of demonstrative pronouns by German monolingual children. In J. Choi, H. Demirdache, \& O. Lungu (Eds.), Language Acquisition at the Interfaces. Proceedings of the GALA 2015 (Generative Approaches to Language Acquisition) (pp. 316-330). Cambridge: Cambridge Scholars Publishing.

Torregrossa, J., Andreou, M., Bongartz. C., \& Tsimpli, I. M. (in press). Bilingual Acquisition of Reference. The role of language experience, executive functions and cross-linguistic effects. Bilingualism, Language and Cognition.

Tsimpli, I. M. (2003). Clitics and Determiners in L2 Greek. In J. M. Liceras, H. Zobl, \& H. Goodluck (Eds.), Proceedings of the 6th Generative Approaches to Second Language Acquisition Conference (GASLA 2002): L2 Links (pp. 331-339). Somerville, MA: Cascadilla Press.

Tsimpli, I. M., \& Dimitrakopoulou, M. (2007). The interpretability hypothesis: evidence from wh-interrogatives in second language acquisition. Second Language Research, 23(2), $215-242$.

Tsimpli, I. M., \& Mastropavlou, M. (2007). Feature interpretability in L2 acquisition and SLI: Greek clitics and determiners. In J. Liceras, H. Zobl, \& H. Goodluck (Eds.), The role of formal features in second language acquisition (pp. 143-169). Mahwah, NJ: Lawrence Erlbaum.

Tsimpli, I. M., \& Papadopoulou, D. (2009). Aspect and argument realization: A study on antecedentless null objects in Greek. Lingua, 116(10), 1595-1615.

Tsimpli, I. M., Peristeri, E., \&Andreou, M. (2013). A study of clitic pronoun production in monolingual and bilingual children with Specific Language Impairment (in Greek).Psixologia, 20(3), 302-320.

Tsimpli, I. M., Peristeri, E., \& Andreou, M. (2016a). Clitic production in monolingual and bilingual children with Specific Language Impairment: Evidence from elicitation and narrative tasks. Linguistic Approaches to Bilingualism. doi: 10.1075/lab.15025.tsi.

Tsimpli, I. M., Peristeri, E., \&Andreou, M. (2016b). Narrative production in monolingual and bilingual children with Specific Language Impairment. Applied Psycholinguistics 37(1), 195-216. 
Tsimpli, I. M., Peristeri, E., \& Andreou, M. (2017). Cross-linguistic influence meets language impairment: Determiners and Object clitics in bilingual children with typical development and with Specific Language Impairment. In L. Cornips, E. Blom, \& Z. Schaeffer (Eds.), Cross-linguistic influence in bilingualism in Bilingualism: A Festschrift for Aafke Hulk (pp.331-353). Amsterdam: John Benjamins Publishing Company.

Tsimpli, I. M., Sorace, A., Heycock, C., \& Filiaci, F. (2004). First language attrition and syntactic subjects: A study of Greek and Italian near-native speakers of English. International Journal of Bilingualism, 8(3), 257-277.

van der Lely, H. K. J. (1997). Narrative Discourse in Grammatical Specific Language Impaired Children: A Modular Language Deficit? Journal of Child Language, 24(1), 221-256.

Vogindroukas, I., Protopapas, A., \& Sideridis, G. (2009). Experiment on the Expressive Vocabulary (Greek version of Renfrew Word Finding Vocabulary Test). Chania, Crete: Glafki.

Wechsler, D. (1992). WISC-III: Wechsler Intelligence Scale for Children-Third Edition: Manual (Australian adaptation). San Antonio, TX: Psychological Corporation.

\section{Appendix}

Gloss Abbreviations

\begin{tabular}{ll}
\hline GLOSS & MEANING \\
\hline ACC & accusative case \\
ACT & active voice \\
AL & Albanian \\
CONJ & conjunctive \\
FEM & feminine gender \\
GR & Greek \\
IMPERF & imperfective aspect \\
IND & indicative \\
MASC & masculine gender \\
NEUT & neuter gender
\end{tabular}




\begin{tabular}{ll}
\hline NOM & nominative case \\
PASS & passive voice \\
PAST & past tense \\
PL & plural number \\
PRES & present aspect \\
RUS & Russian \\
SG & singular number
\end{tabular}


Figures

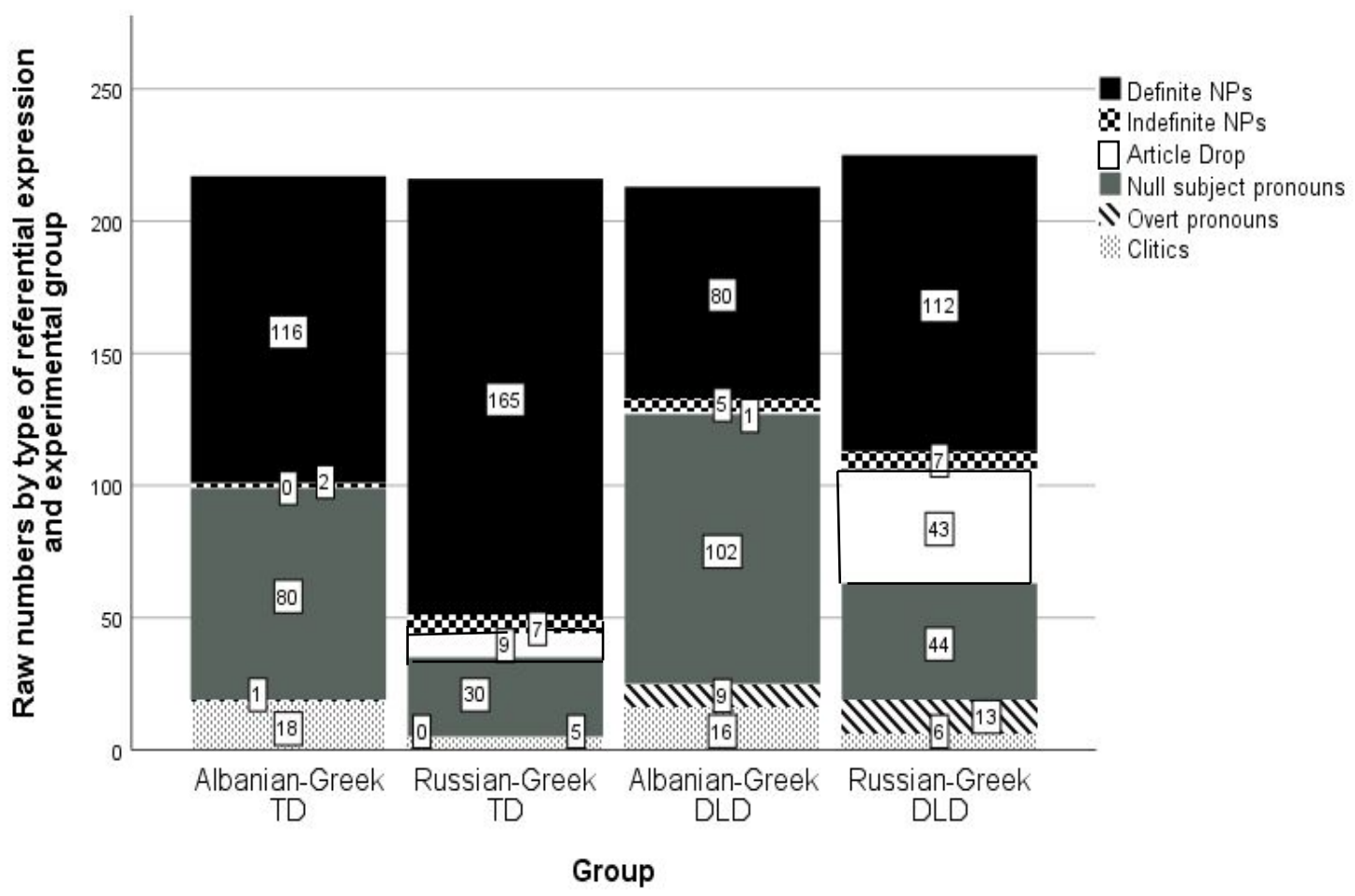

Figure 1. Numbers of different types of referential expressions used in the Maintenance function by experimental group. 


\section{Tables}

Table 1. Groups' mean age, PIQ scores and biodata percentage means (and SDs)

\begin{tabular}{|c|c|c|c|c|}
\hline & $\begin{array}{l}\text { Albanian-Greek TD } \\
(\mathrm{N}=25)\end{array}$ & $\begin{array}{l}\text { Russian-Greek TD } \\
(\mathrm{N}=25)\end{array}$ & $\begin{array}{l}\text { Albanian-Greek DLD } \\
(\mathrm{N}=25)\end{array}$ & $\begin{array}{l}\text { Russian-Greek DLD } \\
(\mathrm{N}=25)\end{array}$ \\
\hline Age & $8.8(2.2)$ & $8.8(1.8)$ & $8.9(2.3)$ & $8.8(2.1)$ \\
\hline PIQ & $115.1(11.9)$ & $110.5(17.0)$ & $109.4(16.7)$ & $104.9(11.5)$ \\
\hline $\begin{array}{c}\text { Home } \\
\text { language } \\
\text { history of } \\
\text { Greek (\%) }\end{array}$ & $40.2(5.6)$ & $39.8(5.1)$ & $40.7(5.5)$ & $38.3(5.9)$ \\
\hline $\begin{array}{c}\text { Current } \\
\text { language use } \\
\text { of Greek (\%) }\end{array}$ & $73.6(3.2)$ & $56.3(5.9)$ & $73.5(2.6)$ & $56.8(5.4)$ \\
\hline
\end{tabular}


Table 2. Groups' mean raw scores (and $S D$ s) in the expressive vocabulary and sentence repetition task.

\begin{tabular}{ccccc}
\hline & $\begin{array}{c}\text { Albanian-Greek TD } \\
(\mathrm{N}=25)\end{array}$ & $\begin{array}{c}\text { Russian-Greek TD } \\
(\mathrm{N}=25)\end{array}$ & $\begin{array}{c}\text { Albanian-Greek DLD } \\
(\mathrm{N}=25)\end{array}$ & $\begin{array}{c}\text { Russian-Greek DLD } \\
(\mathrm{N}=25)\end{array}$ \\
\hline $\begin{array}{c}\text { Expressive vocabulary } \\
\text { (maximum score: } 50)\end{array}$ & $32.1(9.2)$ & $24.3(11.1)$ & $28.0(5.4)$ & $21.3(5.6)$ \\
$\begin{array}{c}\text { Sentence repetition } \\
\text { (maximum score: } 96)\end{array}$ & $61.5(8.1)$ & $54.7(16.8)$ & $51.8(20.2)$ & $48.1(19.7)$ \\
\hline
\end{tabular}

Note: TD: typically developing children; DLD: children with Developmental Language Disorder 
Table 3. Percentages of different types of referentially appropriate (i.e. definite NPs, articledrop, null pronouns, overt pronouns, clitics) and inappropriate expressions (i.e. indefinite NPs) used in the Maintenance function by experimental group.

\begin{tabular}{lcccc}
\hline & $\begin{array}{c}\text { Albanian-Greek } \\
\text { TD }\end{array}$ & $\begin{array}{c}\text { Russian-Greek } \\
\text { TD }\end{array}$ & $\begin{array}{c}\text { Albanian-Greek } \\
\text { DLD }\end{array}$ & $\begin{array}{c}\text { Russian-Greek } \\
\text { DLD }\end{array}$ \\
& $(\mathrm{N}=25)$ & $(\mathrm{N}=25)$ & $(\mathrm{N}=25)$ & $(\mathrm{N}=25)$ \\
\hline Definite NPs & 53.36 & 76.12 & 37.31 & 49.26 \\
Indefinite NPs & 0.66 & 3.31 & 2.33 & 3.07 \\
Article drop & 0 & 4.26 & 0.62 & 19.52 \\
Null subject pronouns & 37.06 & 13.81 & 47.72 & 19.58 \\
Overt pronouns & 0.59 & 0 & 4.26 & 5.83 \\
Clitics & 8.29 & 2.44 & 7.71 & 2.77 \\
\hline
\end{tabular}


Table 4. Summary of logit mixed effects model: Referentially appropriate vs inappropriate expressions.

\begin{tabular}{lcccc}
\hline Predictors & Coefficient & SE & $\mathrm{z}$ & $p$ value \\
\hline Intercept & 88.66 & 4.38 & 20.23 & $<.001^{* * *}$ \\
Disorder & -6.37 & 5.09 & -1.25 & .214 \\
L1 & 7.27 & 5.12 & 1.42 & .158 \\
Disorder * L1 & 1.92 & 2.33 & 0.82 & .411 \\
Age & 0.83 & 0.27 & 3.00 & $.003^{* *}$ \\
\hline
\end{tabular}

Note: TD = typically-developing; DLD = Developmental Language Disorder; L1 = first language; SE = standard error; Disorder levels: TD vs DLD; L1 levels: Albanian vs Russian; Reference level for Disorder: TD; Reference level for L1: Albanian

$* * p<.01, * * * p<.001$ 
Table 5. Summary of logit mixed effects models: Types of referentially appropriate and inappropriate expressions

\begin{tabular}{|c|c|c|c|c|c|c|c|c|c|}
\hline Predictors & & & NPs & & & & & & \\
\hline 8 & $\begin{array}{l}\text { Coefficient } \\
\end{array}$ & SE & $z$ & $p$ value & Coefficient & SE & & & $\begin{array}{l}\text { Coefficient } \\
\end{array}$ \\
\hline Integrcept & 100.34 & 17.07 & 5.87 & $<.001^{* * *}$ & 30.71 & 3.29 & 9.31 & $<.001 * * *$ & \\
\hline Disorder & -27.08 & 27.54 & -.98 & .328 & -15.23 & 2.05 & -7.41 & $<.001^{* * *}$ & 21.72 \\
\hline L110 & -50.27 & 22.81 & -2.20 & $.030^{*}$ & -18.75 & 1.93 & -9.69 & $<.001^{* * *}$ & 61.65 \\
\hline Disorder * L1 & 4.39 & 2.50 & 1.75 & .082 & 9.36 & 4.99 & 1.87 & & -3.71 \\
\hline Agl 1 & -5.82 & 1.88 & -3.08 & $.003^{* *}$ & -1.27 & .33 & -3.74 & $<.001^{* * *}$ & 7.29 \\
\hline
\end{tabular}

Note: TD = typically-developing; DLD = Developmental Language Disorder;

Albanian vs Russian; Reference level for Disorder: TD; Reference level for L1: Albanian

$* p<.05, * * p<.01, * * * p<.001$ 
Table 6. Percentages of grammatical referential expressions and grammatical errors (i.e. articledrops in NPs, null pronouns in obligatory object contexts, and substitution errors (i.e. wrong use of person/case/number/gender feature) on overt pronouns and pronominal clitics) by type and experimental group.

\begin{tabular}{|c|c|c|c|c|}
\hline & $\begin{array}{c}\text { Albanian-Greek } \\
\text { TD } \\
(\mathrm{N}=25)\end{array}$ & $\begin{array}{c}\text { Russian-Greek } \\
\text { TD } \\
(\mathrm{N}=25)\end{array}$ & $\begin{array}{c}\text { Albanian-Greek } \\
\text { DLD } \\
(\mathrm{N}=25)\end{array}$ & $\begin{array}{c}\text { Russian-Greek } \\
\text { DLD } \\
(\mathrm{N}=25)\end{array}$ \\
\hline Grammatical expressions & 96.41 & 92.36 & 89.27 & 59.21 \\
\hline Article drop & 0 & 4.26 & 0.62 & 19.52 \\
\hline Null objects & 0.66 & 1.07 & 3.32 & 16.63 \\
\hline Overt pronoun substitutions & 0 & 0 & 1.33 & 2.14 \\
\hline Clitic substitutions & 2.92 & 2.28 & 5.50 & 2.44 \\
\hline
\end{tabular}

Note: $\mathrm{TD}=$ typically-developing; DLD $=$ Developmental Language Disorder; L1 = first language; $\mathrm{SE}=$ standard error 
Table 7. Summary of logit mixed effects model: grammatical vs ungrammatical referential expressions.

\begin{tabular}{lcccc}
\hline Predictors & Coefficient & SE & Z & $p$ value \\
\hline Intercept & 60.97 & 6.80 & 8.95 & $<.001^{* * *}$ \\
Disorder & 33.16 & 4.24 & 7.81 & $<.001^{* * *}$ \\
L1 & 30.08 & 3.99 & 7.53 & $<.001^{* * *}$ \\
Disorder ${ }^{*}$ L1 & -26.04 & 5.82 & -4.47 & $<.001^{* * *}$ \\
Age & -.20 & .69 & -.28 & .775 \\
\hline
\end{tabular}

Note: TD = typically-developing; DLD = Developmental Language Disorder; L1 = first language; $\mathrm{SE}=$ standard error; Disorder levels: TD vs DLD; L1 levels: Albanian vs Russian; Reference level for Disorder: TD; Reference level for L1: Albanian

$* * * p<.001$ 
Table 8. Summary of logit mixed effects models: Types of grammatical and ungrammatical expressions.

\begin{tabular}{lcccccccccccc}
\hline Predictors & \multicolumn{1}{c}{ Substitution errors } & on overt & pronouns & \multicolumn{3}{c}{ Substitution errors on clitics } \\
\hline & Coefficient & $\mathrm{SE}$ & $\mathrm{z}$ & $p$ value & Coefficient & $\mathrm{SE}$ & $\mathrm{z}$ & $p$ value & Coefficient & SE & $\mathrm{Z}$ & $p$ value \\
Intercept & 2.89 & 1.88 & 1.53 & .129 & 3.60 & 4.05 & .88 & .377 & 3.84 & 7.59 & .50 & .614 \\
Disorder & -2.14 & 1.17 & -1.81 & .072 & -.15 & 2.52 & -.06 & .952 & -15.59 & 4.73 & -3.29 & $.001 * *$ \\
L1 & -.79 & 1.10 & -.72 & .472 & 3.07 & 2.38 & 1.29 & .199 & -13.49 & 4.45 & -3.02 & $.003 * *$ \\
Disorder * L1 & .79 & 1.61 & .49 & .622 & -2.44 & 3.47 & -.70 & .483 & 13.08 & 6.49 & 2.01 & $.047 *$ \\
Age & -.08 & .19 & -.44 & .660 & .13 & .41 & -.31 & .753 & 1.45 & 0.78 & 1.86 & .066 \\
\hline
\end{tabular}

Note: TD = typically-developing; DLD = Developmental Language Disorder; L1 = first language; SE = standard error; Disorder levels: TD vs DLD; L1 levels: Albanian vs Russian; Reference level for Disorder: TD; Reference level for L1: Albanian

$* p<.05, * * p<.01$ 
Table 9. Partial correlations between children's bilingual status and language ability, and appropriate and grammatical referential expressions per experimental group.

\begin{tabular}{|c|c|c|c|c|c|}
\hline Group & & $\begin{array}{c}\text { Home } \\
\text { language } \\
\text { history }\end{array}$ & $\begin{array}{c}\text { Current } \\
\text { language } \\
\text { use } \\
\text { of Greek }\end{array}$ & $\begin{array}{l}\text { Expressive } \\
\text { vocabulary }\end{array}$ & $\begin{array}{l}\text { Sentence } \\
\text { repetition }\end{array}$ \\
\hline Albanian- & Appropriate & .221 & $884 * * *$ & $.581^{*}$ & .085 \\
\hline $\begin{array}{l}\text { Greek TD } \\
(\mathrm{N}=25)\end{array}$ & Grammatical & 298 & .072 & . 154 & .005 \\
\hline Russian- & Appropriate & .011 & .211 & .133 & .032 \\
\hline $\begin{array}{l}\text { Greek TD } \\
(\mathrm{N}=25)\end{array}$ & Grammatical & .029 & .031 & .447 & .351 \\
\hline Albanian- & Appropriate & .102 & $.536 * *$ & .056 & . 194 \\
\hline $\begin{array}{l}\text { Greek DLD } \\
(\mathrm{N}=25)\end{array}$ & Grammatical & .097 & .337 & .113 & 271 \\
\hline Russian- & Appropriate & .011 & .159 & .102 & . 104 \\
\hline $\begin{array}{l}\text { Greek DLD } \\
(\mathrm{N}=25)\end{array}$ & Grammatical & .074 & 256 & . 026 & .132 \\
\hline
\end{tabular}

Note: TD $=$ typically-developing; DLD $=$ Developmental Language Disorder $* p<.05, * * p<.01, * * * p<.001$ 